\title{
Neural mechanisms of sensitivity to peer information in young adult cannabis users
}

\author{
Jodi M. Gilman ${ }^{1,2,3} \cdot$ Randi M. Schuster ${ }^{1,3} \cdot$ Max T. Curran ${ }^{1}$ • \\ Vanessa Calderon $^{1}$ • Andre van der Kouwe ${ }^{2,3}$ - A. Eden Evins ${ }^{1,3}$
}

Published online: 11 April 2016

(C) Psychonomic Society, Inc. 2016

\begin{abstract}
Though social influence is a critical factor in the initiation and maintenance of marijuana use, the neural correlates of influence in those who use marijuana are unknown. In this study, marijuana-using young adults (MJ; $n=20)$ and controls (CON; $n=23)$ performed a decision-making task in which they made a perceptual choice after viewing the choices of unknown peers via photographs, while they underwent functional magnetic resonance imaging scans. The MJ and CON groups did not show differences in the overall number of choices that agreed with versus opposed group influence, but only the MJ group showed reaction time slowing when deciding against group choices. Longer reaction times were associated with greater activation of frontal regions. The MJ goup, compared to CON, showed significantly greater activation in the caudate when presented with peer information. Across groups, caudate activation was associated with selfreported susceptibility to influence. These findings indicate that young adults who use MJ may exhibit increased effort
\end{abstract}

Andre van der Kouwe and A. Eden Evins contributed equally to this work.

Electronic supplementary material The online version of this article (doi:10.3758/s13415-016-0421-8) contains supplementary material, which is available to authorized users.

Jodi M. Gilman jgilman1@partners.org

1 Department of Psychiatry, Center for Addiction Medicine, Massachusetts General Hospital, Boston, MA, USA

2 Department of Radiology, Athinoula A. Martinos Center in Biomedical Imaging, Massachusetts General Hospital, Charlestown, MA, USA

3 Harvard Medical School, Boston, MA, USA when confronted with opposing peer influence, as well as exhibit greater responsivity of the caudate to social information. These results not only better define the neural basis of social decisions, but also suggest that marijuana use is associated with exaggerated neural activity during decision making that involves social information.

Keywords Social influence $\cdot$ Reward $\cdot$ Peer groups · Marijuana $\cdot$ Cannabis $\cdot$ Nucleus accumbens

Marijuana (MJ) is the most widely used drug other than alcohol among young adults; according to the 2011 National Survey on Drug Use and Health, $21.4 \%$ of 18-25-year-old young adults reported using MJ in the past month (SAMHSA, 2011), which is an increase in prevalence from earlier decades (Henry, Oldfield, \& Kon, 2003). It is important to understand the motivations for MJ use, since heavy use in adolescence/ young adulthood has been robustly linked with harms such as future substance dependence (Bergé et al., 2016; Green et al., 2015), worse psychosocial functioning (Lagerberg et al., 2015; Wilkinson, Stefanovics, \& Rosenheck, 2015), and worse academic outcomes (Epstein et al., 2015; Meier, Hill, Small, \& Luthar, 2015; Silins et al., 2015). Young adults may both initiate and continue to use MJ in part due to social factors. Peers play a pivotal role in introducing an individual to a drug (Clayton \& Lacy, 1982; Khavari, 1993), and most drug use occurs in social and recreational settings (TerryMcElrath, O'Malley, \& Johnston, 2009). Furthermore, in a survey of $106 \mathrm{MJ}$ users, almost half cited social pressure as a motive for using (Hartwell, Back, McRae-Clark, Shaftman, $\&$ Brady, 2012). Although the impact of social influence on behavior is greater in younger than in older adults broadly (Gardner \& Steinberg, 2005), it remains poorly understood whether susceptibility to peer influence is further exaggerated 
in young adults who use $\mathrm{MJ}$ and, if so, whether this is reflected in unique patterns of brain activity. The purpose of the present study is to establish an association between susceptibility to social influence and MJ use, as this relationship could indicate that susceptibility to influence is a preexisting risk factor, and/or a neurodevelopmental outcome, of MJ exposure.

Scientists have used functional magnetic resonance imaging (fMRI) to establish that structures such as the nucleus accumbens (NAc), caudate, amygdala, cingulate, and anterior insula are activated when individuals make decisions in the context of peer influence. These regions are associated with social reward and learning, social cognition, and physiological arousal and anxiety, indicating that conforming to or deviating from social norms may generate a variety of emotional responses (e.g., Berns, Capra, Moore, \& Noussair, 2010; Berns et al., 2005; Klucharev, Hytonen, Rijpkema, Smidts, \& Fernandez, 2009). Neural sensitivity to peer influence appears to be especially salient in striatal regions. One of the first studies to use fMRI to study social influence demonstrated that the caudate was more active when participants saw "popular" than when they saw "unpopular" symbols (Mason, Dyer, \& Norton, 2009). In a study in which participants rated the attractiveness of faces before and after receiving information about how their peers rated each face, deactivation of the NAc during a conflict with group opinion predicted conformity in future trials (Klucharev et al., 2009). Another study using ratings of facial attractiveness showed that agreeing with peers increased activity in the NAc, whereas disagreeing decreased NAc activity (Zaki, Schirmer, \& Mitchell, 2011). These studies suggest that individuals process both the rewarding aspects of social stimuli and the congruence of consensus with other people using traditional reward circuitry such as the caudate and the NAc (Zaki et al., 2011).

Many studies have supported the ideas that peer opinion can affect neural response, particularly during adolescence (e.g., Guyer et al., 2014; Masten et al., 2009; Pfeifer et al., 2011; Welborn et al., 2016), and that caudate activity may be a marker of social reward in typically developing adolescents (Guyer et al., 2014). Chronic peer conflict has been shown to be associated with greater risk-taking behavior and heightened activation in brain regions involved in affect and reward processing, such as the striatum and insula (Telzer, Fuligni, Lieberman, Miernicki, \& Galvan, 2015). A series of studies showed that during risk tasks such as simulated driving experiments, as well as during nonrisky decision-making tasks, being observed by peers elicited striatal activation in adolescents (Chein, Albert, O’Brien, Uckert, \& Steinberg, 2011; A. R. Smith, Steinberg, Strang, \& Chein, 2015). In addition, a behavioral study in which people rated risky behaviors before and after observing peer ratings of those behaviors revealed a steady decline in social conformity from late childhood through adulthood (Knoll, Magis-Weinberg, Speekenbrink,
\& Blakemore, 2015). These findings together support the idea that the striatum is sensitive to social context and can be linked to individual differences in sensitivity to peer influence, particularly in adolescents. In addition to the literature on the neural correlates of peer effects, a growing literature is concerned with the effects of MJ on the brain. The main psychoactive component of cannabis, $\Delta$-9-tetrahydrocannabinol (THC), acts as a direct agonist of cannabinoid CB1 receptors in the brain (Downer, Boland, Fogarty, \& Campbell, 2001; Heath, Fitzjarrell, Fontana, \& Garey, 1980; Lawston, Borella, Robinson, \& Whitaker-Azmitia, 2000; Scallet et al., 1987), which are highly expressed in regions involved in the regulation of mood and cognition (amygdala, striatum, prefrontal cortex, and hippocampus). There is now a wellestablished relationship between regular MJ use and a range of potentially adverse outcomes, including effects on learning and cognition (see Solowij \& Battisti, 2008, and Solowij, Stephens, Roffman, \& Babor, 2002, for reviews), effects on brain structure and function (see Lorenzetti, Solowij, Fornito, Lubman, \& Yucel, 2014, for a review), and potential impacts on mental health (Hall \& Degenhardt, 2009). Cannabis appears to affect both ventral (including the NAc) and dorsal (caudate and putamen) striatum function. The striatum has a central role in the mechanisms of reward; as such, its dysregulation is thought to relate to the anhedonia and amotivation that is often observed with MJ use (Nestler \& Carlezon, 2006). Activation of the ventral striatum/NAc is associated with acute MJ use, and in fact, data indicate an increase in dopamine concentrations of $136 \%$ in the human ventral striatum during cannabis administration (Bossong et al., 2009). THCexposed rats showed structural changes in the NAc (e.g., increases in the length of dendrites and in the number of dendritic spines; Kolb, Gorny, Limebeer, \& Parker, 2006), with similar increases in the NAc being reported in human MJ users (Gilman et al., 2014). Functional MRI studies have also revealed greater activation of the caudate and putamen in heavy cannabis users versus nonusers during tasks that are dependent on the dorsal striatum memory system (e.g., Ames et al., 2013; Bohbot, Del Balso, Conrad, Konishi, \& Leyton, 2013), and greater activation of the caudate during the Iowa gambling task (Acheson et al., 2015), indicating that all subregions of the striatum are likely impacted by MJ use.

Few studies have specifically investigated peer influence within substance-using individuals, and none have specifically investigated this association among individuals who use MJ. A recent developmental neuroscience study that investigated the links between resting-state activity of the reward circuitry and substance use demonstrated that among adolescents who used alcohol, MJ, and cigarettes, the earlier they initiated substance use, the greater the strength of connectivity between the NAc and frontal regions (Weissman et al., 2015). This study fits nicely with the larger body of research showing that adolescent impulsivity and/or novelty seeking can be 
explained in part by maturational differences in frontal cortical and subcortical monoaminergic systems (see Chambers, Taylor, \& Potenza, 2003, for a review). However, the lack of studies directly addressing peer influence, reward circuitry, and substance use indicates a fundamental gap in the literature that the present study sought to address.

In the present study, we adapted a task used in a series of classical social psychology experiments in the 1950s by psychologist Solomon Asch (1951, 1952, 1956). Asch used a simple paper-and pencil line judgment task to demonstrate that individuals were likely to agree with peers even at the expense of accuracy. We chose to use an objective task in which there are "right" and "wrong" answers (in contrast to subjective tasks such as rating the attractiveness of faces or the likability of music), in order to create a scenario in which going along with the group would have negative consequences if the group suggested an incorrect answer. This paradigm may be more analogous to the social influence surrounding drug use, in which there is a cost to following substance-using peers. For the purpose of this study, social influence was defined in two ways: (1) sensitivity to peer information in general (as compared to no peer information), and (2) likelihood of conforming to (as compared to dissenting from) peer opinion. We hypothesized that sensitivity to peer information would be reflected in greater caudate activation in the MJ than in the CON group, and that the likelihood of conforming to peer opinion would be reflected in greater NAc activation in the MJ than in the CON group.

\section{Method}

\section{Participants}

Our participants were 43 young adults, ages 18-25 years: 20 of whom used MJ at least once a week (MJ), and 23 agematched controls (CON). We chose to study light to moderate users, rather than heavy users, because evidence suggests that peer influence may have more of an impact in recreational users than it in substance-dependent individuals, whose drug-taking may become less social and more habitual or compulsive (Wise, 1996). This sample size was calculated on the basis of previous studies that had used neuroimaging paradigms to investigate the correlates of social influence (Berns et al., 2010; Berns et al., 2005; Klucharev et al., 2009). The MJ group were asked to refrain from using all substances on the day of the study. The CON group had used $\mathrm{MJ}$ on fewer than five lifetime occasions and had not used MJ in the past 3 months. All participants were medically healthy, with no current psychiatric disorders (verified by the Structured Clinical Interview for DSM-IV Non-Patient Version-SCID; First, Spitzer, Miriam, \& Williams, 2002), except for cannabis use disorders in the MJ group.
Participants who met current or lifetime abuse or dependence criteria for any drug, including alcohol and nicotine, were excluded, though prior use of other drugs was not exclusionary (see Table 1). All of the participants gave written informed consent to a protocol approved by the Partners Human Research Committee Institutional Review Board.

\section{Measures}

The MJ participants completed a timeline follow-back (Sobell, Sobell, Klajner, Pavan, \& Basian, 1986) asking them to indicate, for the past 90 days, the days on which they had used MJ. Their cumulative number of joints (or joint equivalents), number of joints per week, and number of joints per day were calculated for the 90 days prior to the study. All participants also completed a timeline follow-back for alcohol use (Sobell et al., 1986), to detail their drinking behavior over the past 90 days, resulting in an estimate of the past threemonth standard drink consumption. We chose to include the timeline follow-back for alcohol to ensure that alcohol use patterns were not different between the two groups. All participants also completed the Ten-Item Personality Inventory (TIPI; Gosling, Rentfrow, \& Swann, 2003) to assess their personality characteristics.

Participants also completed the Multidimensional Iowa Suggestibility Scale (MISS; Kotov, Bellman, \& Watson, 2004), which assesses self-reported susceptibility to influence in five social domains: consumer suggestibility (e.g., suggestibility to commercials, products), persuadability (e.g., changing one's mind on the basis of other peoples' arguments), physiological suggestibility (e.g., feeling cold when someone else is shivering), physiological reactivity (e.g., feeling jumpy after watching a scary movie), and peer conformity (e.g., liking the same celebrities/fashion/music as friends). The scores across subscales were summed, with higher total values indicating greater suggestibility. Because the aim of the present study was to understand the relationship between peer influence and brain activation, only the peer conformity subscale was regressed against activation in our predetermined regions of interest (ROI).

\section{Social influence task design}

The social influence task was designed to measure an individual's likelihood of following group decisions or making independent choices in a visual discrimination task, and was based on a task previously developed by our group (Gilman et al., 2016). Each trial consisted of five events, shown in Fig. 1. There were 44 total trials, each consisting of five events. The 44 trials were split into two runs of 22 trials each. Each trial took $16 \mathrm{~s}$, and the task took approximately $20 \mathrm{~min}$ to complete. 
Table 1 Participant demographics

\begin{tabular}{|c|c|c|c|}
\hline & & $\begin{array}{l}\mathrm{CON} \\
(n=23)\end{array}$ & $\begin{array}{l}\text { MJ } \\
(n=20)\end{array}$ \\
\hline \multicolumn{2}{|l|}{ Gender } & $11 \mathrm{M} / 12 \mathrm{~F}$ & $9 \mathrm{M} / 11 \mathrm{~F}$ \\
\hline Age & Years & $21.6(1.9)$ & $20.6(2.5)$ \\
\hline Education & Years & $15.1(1.4)$ & $14.2(1.8)$ \\
\hline \multirow[t]{5}{*}{ TIPI } & Extroversion & $7.5(2.8)$ & $8.9(3.5)$ \\
\hline & Agreeableness & $10.2(1.9)$ & $9.9(2.1)$ \\
\hline & Conscientiousness & $11.5(2.0)$ & $9.9(2.6)^{\mathrm{a}}$ \\
\hline & Emotional stability & $11.5(1.8)$ & $10.6(2.7)$ \\
\hline & Openness & $11.2(2.5)$ & $11.7(1.9)$ \\
\hline \multicolumn{4}{|l|}{ Substance Use } \\
\hline Alcohol & \# Drinks/week & $2.4(2.4)$ & $2.8(2.0)$ \\
\hline Cigarettes & \# Occasional smokers & 0 & 7 \\
\hline \multirow[t]{4}{*}{ Marijuana } & \# MJ use days/week & 0 & $2.7(1.2)$ \\
\hline & \# MJ joints per week & 0 & $6.6(7.5)$ \\
\hline & Age of onset (years) & 0 & $18.3(2.0)$ \\
\hline & Duration of use (years) & 0 & $2.3(1.5)$ \\
\hline \multirow[t]{8}{*}{ Suggestibility } & Consumer suggestibility & $18.0(4.7)$ & $20.3(6.3)$ \\
\hline & Persuadability & $41.4(6.5)$ & $43.4(8.4)$ \\
\hline & Physiological suggestibility & $18.4(3.3)$ & $18.8(4.6)$ \\
\hline & Physiological reactivity & $41.4(6.4)$ & $43.8(6.4)$ \\
\hline & Peer conformity & $20.6(7.0)$ & $24.6(6.8)^{b}$ \\
\hline & Mental control & $38.7(8.2)$ & $38.1(9.6)$ \\
\hline & Unpersuadability & $53.7(6.6)$ & $53.0(8.8)$ \\
\hline & Total suggestibility & $139.8(15.7)$ & $150.8(22.4)^{b^{*}}$ \\
\hline
\end{tabular}

All values are expressed in means and standard deviations. There were no significant differences between groups on any measure other than conscientiousness. ${ }^{\mathrm{a}} p=.03,{ }^{\mathrm{b}} p=.07$

\section{Social Influence Experiment: Task Events}

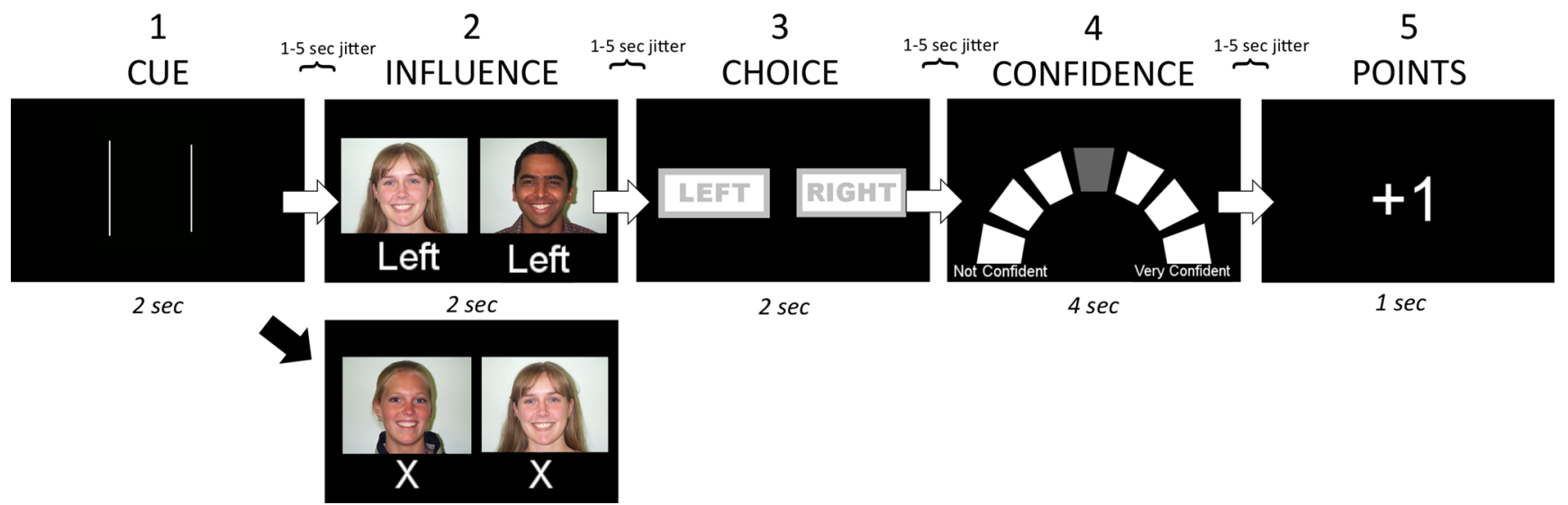

Fig. 1 Social influence task. This task consisted of five events, described in the Method section, that represent different phases of decision making. In Event 1 (Cue), participants were presented with two lines and asked to judge which line was longer. In Event 2 (Influence), two photographs of fictitious "previous participants" were shown. The participant was either presented with "peer" responses (top) or was not shown responses; instead, participants would see only an " $\mathrm{X}$ " under each photograph (bottom). In Event 3 (Choice), participants were asked to make a choice, and could either agree or disagree with the peer responses in Event 2. In Event 4 (Confidence), they were asked to rate their confidence in their decision. In Event 5 (Feedback), they could earn one point for a correct response (or none for an incorrect response). All events were jittered with a fixation crosshair that was presented for a random noninteger interval between 1 and $5 \mathrm{~s}$ 
In Event 1 (Cue), the participant saw a cue, consisting of two lines, and was asked to judge whether the left or the right line was longer. In approximately $20 \%$ of the trials (eight trials), the task was "easy" (i.e., participants could easily tell which was longer, yielding a $<5 \%$ error rate); in the other $80 \%$ of the trials (36 trials), the task was "difficult" (yielding an $\approx 50 \%$ error rate). We chose to make the majority of trials difficult because we found in piloting the task that participants rarely conformed to group influence on easy trials. In Event 2 (Influence), two photographs of fictitious "previous participants" with responses were revealed to the participant. These photographs were taken from the Texas Center for Vital Longevity at the University of Texas, Dallas (happy expressions, ages 18-29; Minear \& Park, 2004), and the Max Plank FACES database (happy expressions, young adults ages 19-31; Troje \& Bülthoff, 1996). Participants were given a binder of 32 color photographs (16 of each gender) before beginning the task, and were allowed to select eight peers; this was done to create an affiliation between the participant and the "participants" in the photographs (Polonec, Major, \& Atwood, 2006). In 28 of 44 trials, both peers showed the same response (both chose either "left" or "right"), and the participant could either agree or disagree with these peers. In six trials, the peer responses were split, so that one peer chose "right" and one chose "left". The split condition was not analyzed, but was included only to make the task believable (i.e., participants would get suspicious if there were no trials in which the peers were split). In ten trials, participants were not shown responses from the peers; instead of responses, they would see only " $\mathrm{X}$ " under each photograph. In $50 \%$ of the difficult trials (14 trials), the "group" responses were correct (e.g., the line on the left was longer, and the "group" recommended "left"), and in the other $50 \%$ (14 trials), the "group" was incorrect (e.g., the line on the left was longer but the "group" recommended "right"). These two conditions were combined, since group accuracy did not affect choice behavior, which was at chance level for difficult trials. The "group" was always correct on easy trials in order to increase the believability of the task (Fig. 1). The trial types were presented in a random order. In Event 3 (Choice), participants chose which line segment they judged to be longer ("Left" or "Right"). In Event 4 (Confidence), participants were asked to rate their confidence in that judgment on a 7-point Likert scale. In Event 5 (Points), participants were told whether they were correct on that trial. If participants made the correct judgment, they received a point. A monetary reward was given at the end of the experiment based on the number of points received (over 40 points $=\$ 20,30-39$ points $=\$ 15,20$ 29 points $=\$ 10$, and 10-19 points $=\$ 5$ ). This experiment was programmed in Python 2.7 using the package PyGame (www. pygame.org/), version 1.9.2.

Participants answered questions after the scan about how likely they were to go against group responses. Answers ranged, on a Likert scale, from very unlikely to very likely.

\section{Behavioral analysis}

We conducted repeated measures analyses of variance (ANOVAs; SPSS, version 16) to assess differences in behavior between the groups. The independent variable was group (CON, MJ), and the dependent variable was choice (congruent with the "group," incongruent with the "group"). We conducted ANOVAs to investigate whether reaction times (i.e., the time from being presented with the choices "Left" and "Right" in Event 3 to pressing a button to designate a response) and/or confidence ratings in Event 4 differed between groups or across conditions (i.e., when choice was congruent or incongruent with the group). Significant main effects and Group $\times$ Condition interactions were followed up with posthoc Tukey tests. We also conducted linear regression models based on MISS peer conformity scores, postscan questionnaire scores, and neural activation in a priori ROIs across groups.

\section{Acquisition and analysis of neuroimaging data}

Participants were scanned using a 3-T Skyra Siemens (Erlangen, Germany) scanner with a 32-channel head coil at the Massachusetts General Hospital (MGH) Martinos Center for Biomedical Imaging. Whole-brain T1-weighted 1-mm isotropic structural scans were collected using a 3-D multiecho MPRAGE sequence (176 sagittal slices, $256 \mathrm{~mm}$ FoV, TR 2, $530 \mathrm{~ms}$, TI 1,200 ms, 2x GRAPPA acceleration, TE 1.64/3.5/ 5.36/7.22 ms, BW $651 \mathrm{~Hz} / \mathrm{px}, \mathrm{T}_{\text {acq }}$ 6:03 min; van der Kouwe, Benner, Salat, \& Fischl, 2008). Functional scans were collected using a 2-D gradient echo EPI sequence (31 slices, $3 \mathrm{~mm}$ thick, 0.6-mm gap, 216-mm FoV, $3 \times 3 \mathrm{~mm}^{2}$ in-plane resolution, TR 2 s, TE $30 \mathrm{~ms}$, BW $2240 \mathrm{~Hz} / \mathrm{px}$ ). All acquisitions were automatically positioned using AutoAlign (van der Kouwe et al., 2005).

Data processing was carried out using FEAT (fMRI Expert Analysis Tool), version 5.98, part of the FSL fMRI processing stream (fMRIB's Software Library, www.fmrib.ox.ac.uk/fsl). Each participant's functional and structural scans were registered using FSL's linear registration tool (FLIRT), and then these scans were registered to high-resolution structural and standard space images using both FLIRT and FSL's nonlinear registration tool (Jenkinson \& Smith, 2001), so that each participant's brain was registered to the ICBM152 T1 template (Chau \& McIntosh, 2005). In addition, the following preprocessing was applied; nonbrain removal using FSL's brain extraction tool (Smith, 2002); spatial smoothing using a Gaussian kernel of $5 \mathrm{~mm}$ full width at half maximum; grandmean intensity normalization of the entire 4-D dataset; highpass temporal filtering (Gaussian-weighted least-squares straight-line fitting, with sigma $=50.0 \mathrm{~s}$ ). The analysis was performed in two steps. First, each participant's time series data were fitted using a linear signal model with 11 regressors 
of interest and six movement regressors of no interest. The regressors of interest included the following explanatory variables (EVs): (1) cue presentation, (2) influence (e.g., both peers showing the same response), (3) no influence (e.g., Xs displayed below the peers), (4) split influence (e.g., one peer chose "right" and one chose "left"), (5) choice after influence in which the participant followed the group, (6) choice after influence in which the participant dissented from the group, (7) choice after no influence, (8) choice after split influence, (9) confidence, (10) positive feedback (point-based gains), and (11) negative feedback (no gains). We modeled our regressors using FSL's three-column format, in which each event was programmed with a triplets of numbers, consisting of the onset of the event (in seconds), the duration (in seconds) of the event, and the weight of the input (all were assigned a weight of 1). Events were averaged and convolved using a gamma waveform. The experiment was jittered through the inclusion of a fixation point presented between task events. This fixation point was presented for a random time interval between 1 and $5 \mathrm{~s}$ (at a noninteger value), which allowed us to separate the events of a trial for analysis.

Next, higher-level group analysis was carried out using FLAME (FMRIB's Local Analysis of Mixed Effects), Stage 1 and Stage 2 (Woolrich et al., 2009). To correct for multiple comparisons, $Z$ (Gaussianized $\mathrm{T} / \mathrm{F}$ ) statistic images were thresholded using clusters determined by $Z>2.3$ and a (corrected) whole-brain cluster significance threshold of $p<$ .05 (Worsley, 2001). Our analysis consisted of a whole-brain, random-effects analysis of two primary contrasts of interest, which reflected our hypotheses regarding social influence: (1) response to influence versus no influence, which isolated areas of the brain that responded to group information in general (e.g., EV 2 vs. 3), and (2) congruent versus incongruent choices, which isolated brain areas that showed different responsivity to following versus dissenting from group information (e.g., EV 5 vs. 6). Participants with too few responses (five or fewer) were removed from the second analysis, since these participants had too few responses to accurately estimate their neural response to these events. The other task events were necessary in order to model the task, but were not included in the primary analysis.

In parallel with our whole-brain analyses, individual parameter estimates for an ROI analysis were extracted using the FSL program featquery (http://fsl.fmrib.ox.ac.uk/fsl/fs14.0/feat5/ featquery.html). Because we had a priori, anatomically focused hypotheses regarding the caudate and NAc, we chose an ROI approach in order to determine whether there was evidence of task-related changes in brain activity within these regions and whether this activation correlated with the behavioral outputs. We chose to use an ROI approach in order to (1) reduce the number of voxels to a single mean data point, yielding measurements that were less variable than the voxel-level measurements, and (2) to mitigate the multiple-comparisons issue, which provided increased sensitivity to detect task-related differences in brain activity (Bowman, Guo, \& Derado, 2007). We extracted the data from each participant from both the NAc and the caudate (see Fig. 4a below, which illustrates the anatomical masks used). The activation signal was extracted using the following steps: (1) The signal at each voxel was converted to a (percentage) deviation from the mean for that voxel across the entire time series, (2) the signal was averaged by stimulus type and spatially translated into the Montreal Neurological Institute (MNI) space, and (3) anatomical masks were designated consisting of the volume of interest through which each individual participant's data were extracted. All masks were parcellated from the ICBM152 T1 brain at the MGH Center for Morphometric Analysis (Gasic et al., 2009; Perlis et al., 2008), using validated anatomical landmarks for the NAc and caudate.

\section{Results}

\section{Participant characteristics}

The CON and MJ groups were not different in gender, age, or years of education (Table 1). Group MJ reported a trend for greater peer conformity $(p=.07)$ and greater suggestibility $(p=.07)$ than in Group $\mathrm{CON}$, and $\mathrm{CON}$ reported greater conscientiousness than $\mathrm{MJ}(p=.03)$. These personality measures were not related to task behavior, self-reported task behavior, or MISS scores.

\section{Behavioral results}

We found a main effect of choice type $[F(1,41)=36.27, p<$ $\left..0001, \eta_{\mathrm{p}}{ }^{2}=.469\right]$ (Fig. $2 \mathrm{a}$ ), such that both the CON and MJ groups were more likely to make congruent than incongruent choices. CON participants had averages of 12.0 congruent $(S D=2.7$, range $=8-18)$ and 7.9 incongruent $(S D=2.6$, range $=2-13$ ) responses. $\mathrm{MJ}$ participants had averages of 12.2 congruent $(S D=2.6$, range $=8-16)$ and 7.0 incongruent $(S D=$ 2.4 , range $=2-11$ ) responses. There was no main effect of group or Group $\times$ Choice Type interaction, indicating that choice behavior did not differ between the groups, but that both groups preferred to follow the group responses.

However, a Group $\times$ Choice Type (congruent, incongruent, "split," or "none") interaction did emerge for reaction times $\left[F(1,41)=4.86, p=.03, \eta_{p}{ }^{2}=.10\right]$. Post-hoc tests indicated that $\mathrm{MJ}$ participants had longer reaction times when making choices incongruent to peer responses than for choices congruent with peer responses, whereas CON showed no difference in reaction times between congruent and incongruent responses (Fig. 2b). Additionally, we observed a main effect of choice type on confidence ratings $[F(3,39)=14.83$, $\left.p<.001, \eta_{\mathrm{p}}{ }^{2}=.503\right]$, indicating that both groups were more confident when agreeing with than when 


\section{A Social influence effect}

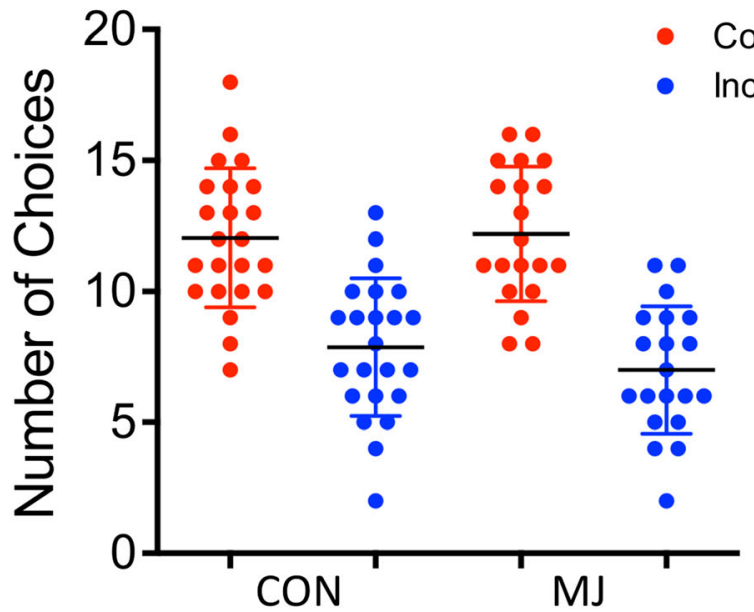

\section{B Reaction times and confidence effects}
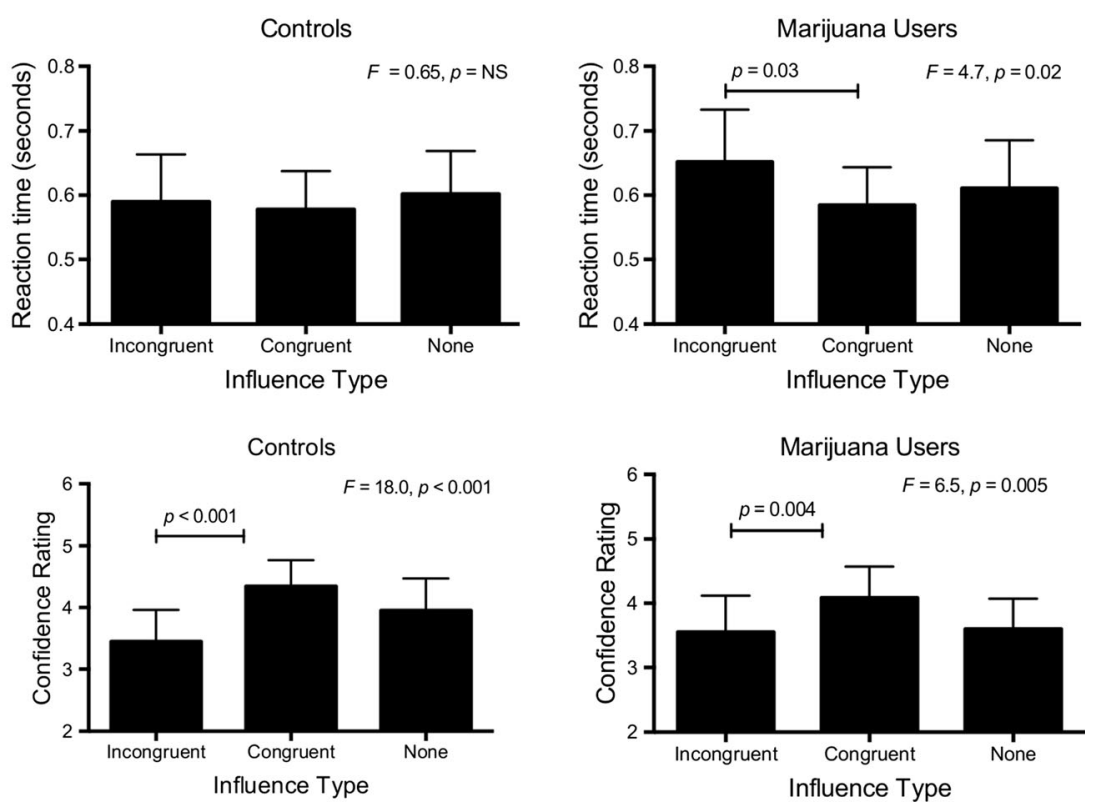

Fig. 2 (a) Choice behavior in the social influence task. All participants were more likely to follow than to go against the group responses; there were no significant differences between groups. Each point represents an individual participant; the black line represents the mean, and the colored lines represent the $95 \%$ confidence intervals. (b) Confidence and reaction time measures. Controls (top left) did not show

disagreeing with the group responses (Fig. 2b). There was no main effect of group or Group $\times$ Confidence interaction, nor a group difference in points earned and money received $(p=.72)$. See Table $\mathrm{S} 1$ for descriptive statistics on task behavior.

\section{Neuroimaging results}

\section{Activation to social influence versus no influence}

(whole-brain analysis) The following brain-imaging results

modulation of reaction times across conditions. Group MJ (top right) showed a significant effect of choice type on reaction times, responding more slowly for choices that were incongruent with the group responses. For confidence ratings, both controls (bottom left) and MJ users (bottom right) reported greater confidence when agreeing than when disagreeing with the group responses

refer to changes in activity during Event 2, Influence, in which participants were or were not shown group responses (Table 2). When participants saw information from faces with peer responses, as compared to no peer information, voxel-based analyses showed a main effect of social influence across a broad network of brain regions associated with social cognition and decision making, predominantly frontal structures such as the rostral cingulate zone (RCZ), dorsolateral prefrontal cortex (DLPFC), and bilateral caudate (Fig. 3, far left). When 
Table 2 Activation to social influence

\begin{tabular}{|c|c|c|c|c|c|c|c|}
\hline Area & HEM & Region & $x$ & $y$ & $z$ & $Z$ Stat & VOL \\
\hline \multicolumn{8}{|c|}{ Activation in CONTROLS } \\
\hline \multirow[t]{3}{*}{ Occipital } & $\mathrm{R}$ & Lateral occipital cortex & 28 & -76 & 28 & 3.76 & 61 \\
\hline & $\mathrm{R}$ & Occipital cortex & 30 & -86 & -2 & 3.74 & 118 \\
\hline & $\mathrm{L}$ & Lateral occipital cortex & -26 & -90 & -2 & 4.42 & 204 \\
\hline \multicolumn{8}{|c|}{ Activation in MJ Participants } \\
\hline \multirow[t]{6}{*}{ Frontal } & $\mathrm{L} / \mathrm{R}$ & Rostral cingulate zone & 6 & 48 & 32 & 4.60 & 853 \\
\hline & $\mathrm{L} / \mathrm{R}$ & Medial frontal cortex & 4 & 44 & -14 & 3.74 & 52 \\
\hline & $\mathrm{R}$ & Orbitofrontal cortex & 46 & 30 & -8 & 3.95 & 143 \\
\hline & $\mathrm{R}$ & Inferior frontal gyrus & 52 & 22 & 14 & 4.03 & 142 \\
\hline & $\mathrm{L}$ & Inferior frontal gyrus & -48 & 10 & 20 & 4.07 & 395 \\
\hline & $\mathrm{L}$ & DLPFC & -46 & 0 & 36 & 3.92 & 123 \\
\hline Parietal & $\mathrm{L} / \mathrm{R}$ & Precuneus & 4 & -56 & 24 & 4.75 & 582 \\
\hline \multirow[t]{2}{*}{ Occipital } & $\mathrm{L} / \mathrm{R}$ & Lingual gyrus & -4 & -76 & -2 & 3.81 & 138 \\
\hline & $\mathrm{L}$ & Occipital pole & -30 & -94 & -4 & 3.82 & 115 \\
\hline \multirow[t]{3}{*}{ Subcortical } & $\mathrm{R}$ & Caudate & 12 & 10 & 8 & 4.53 & 208 \\
\hline & $\mathrm{L}$ & Caudate & -14 & 12 & 8 & 3.79 & 125 \\
\hline & $\mathrm{L}$ & Insula & -34 & 20 & 0 & 3.87 & 100 \\
\hline \multicolumn{8}{|c|}{ MJ $>$ CONTROLS } \\
\hline \multirow[t]{2}{*}{ Subcortical } & $\mathrm{R}$ & Caudate & 12 & 10 & 6 & 3.35 & 95 \\
\hline & $\mathrm{R}$ & Caudate & 6 & 2 & 2 & 3.10 & 16 \\
\hline
\end{tabular}

$Z$ (Gaussianized T/F) statistic images were thresholded using clusters determined by $Z>2.3$ and a (corrected) whole-brain cluster significance threshold of $p<.05$. HEM represents the hemisphere. Coordinates are in MNI space. VOL $=$ volume, in number of voxels $\left(2 \times 2 \times 2 \mathrm{~mm}^{3}\right)$.

we examined each group separately, we observed that the MJ group was driving this main effect, with significant activation in the caudate, $\mathrm{RCZ}$, inferior frontal gyrus (IFG), and DLPFC, whereas the CON group showed significant activation only in occipital structures. When directly comparing $\mathrm{MJ}$ and $\mathrm{CON}$, MJ showed significantly greater activation than $\mathrm{CON}$ in the right caudate (Fig. 3, far right). To test whether the caudate difference was modulated by other variables, we ran an ANOVA with caudate activation as the dependent variable, group membership (MJ, CON) as the independent variable, and covariates of interest including alcohol use, age, gender, and personality. We found that the significant predictors of caudate activation included group $\left[F=15.10, p<.001, \eta^{2}=.31\right]$ and age $\left[F=7.10, p<.012, \eta^{2}=.18\right]$. Alcohol use and personality measures did not predict caudate activation.

\section{Activation to choice during congruent versus incongruent} decisions (whole-brain analysis) These brain-imaging results refer to changes in activity during Event 3, Choice, in which participants could choose either to follow the group's

Brain Activation to Event 2, Influence (Revealed Responses > Control (" $X$ "))
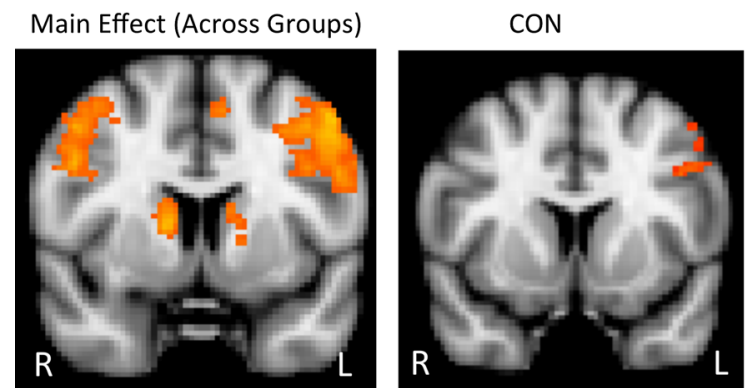

Fig. 3 Regions associated with social influence in Groups CON and MJ. The contrast of social influence versus no influence activated a wide network of structures in both groups (see the leftmost figure for the main effect of influence across groups). Notably, the caudate was only activated in the MJ group. The difference image (rightmost figure)
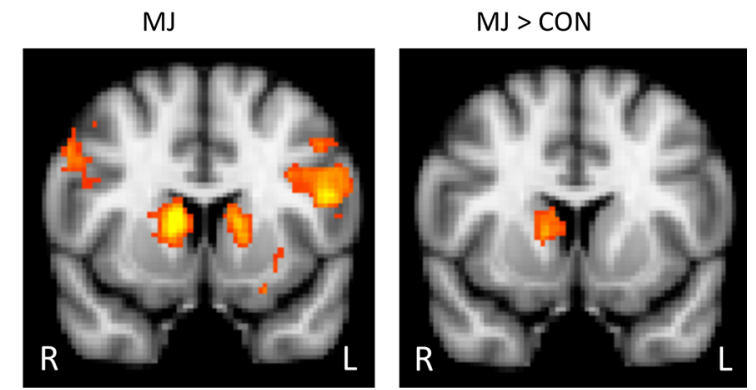

demonstrates that MJ showed significantly greater activation than CON to social influence in the right caudate. All clusters shown were thresholded using clusters determined by $Z>2.3$ and a (corrected) whole-brain cluster significance threshold of $p<.05$ 
recommendation (congruent) or to go against the group response (incongruent). Four participants in the CON group and four in the MJ group were removed from this analysis because they had too few incongruent responses (e.g., five or fewer). Across groups, participants showed greater activation when making congruent than when making incongruent choices in numerous brain regions, including bilateral anterior and posterior cingulate, frontal medial cortex, as well as in occipital regions. Across groups, participants showed greater responses to incongruent than to congruent choices in frontal regions (right middle frontal gyrus and right frontal pole) and bilateral lateral occipital cortex (Table S2). There were no differences between $\mathrm{CON}$ and $\mathrm{MJ}$ in activation to congruent or incongruent decisions.

\section{Correlations between self-reported peer conformity}

and brain activation To investigate whether self-reported peer conformity correlated with brain activation, data were extracted from the ROIs in the caudate and the NAc of each participant (Fig. 4a) and regressed against scores on the MISS, as well as self-reported task behavior. Self-reported tendency toward peer conformity, as assessed with the MISS, correlated with activation in the caudate in Event 2, Influence (minus no influence), across groups on both the left $\left(r^{2}=.17, p=.006\right)$ and right $\left(r^{2}=.25, p<.001\right)$ (Fig. $4 \mathrm{~b}$, top). There were no differences in slopes between MJ and CON, indicating that both groups showed similar effects, though the groups did differ in their magnitudes of caudate activation $(t=$ 2.89, $p=.006$ ) (Fig. 4c, top). Self-reported peer conformity scores did not correlate with NAc activation. To explore whether other brain regions also correlated with self-reported peer conformity, we ran an additional analysis in which the peer conformity scores were regressed into the whole-brain random-effects analysis. The correlation between caudate activation and peer conformity revealed several interesting clusters, including bilateral caudate and bilateral NAc, but these clusters were generally small and did not survive whole-brain correction (see Table S3 and Fig. S1).

Postscan questionnaire responses correlated with actual task behavior, as well as with activation in the NAc in response to choice behavior. We found a strong relationship between self-reported likelihood of going along with the group on the task and the actual number of congruent

\section{A Anatomical Masks B Correlations between Activation and Self-Reported Conformity}

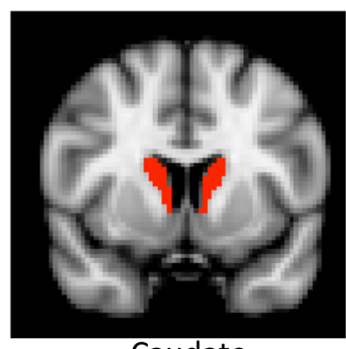

Caudate

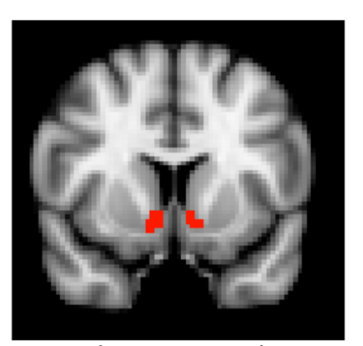

Nucleus Accumbens

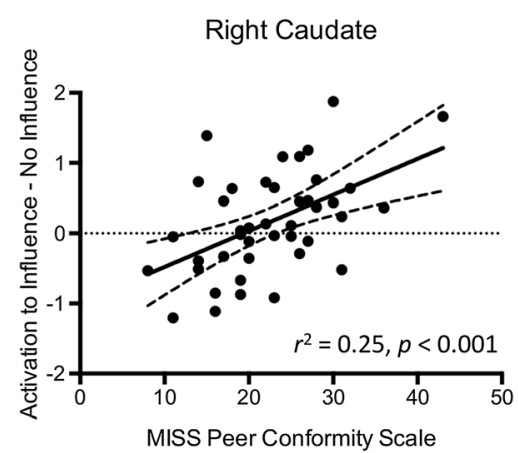

Right Nucleus Accumbens

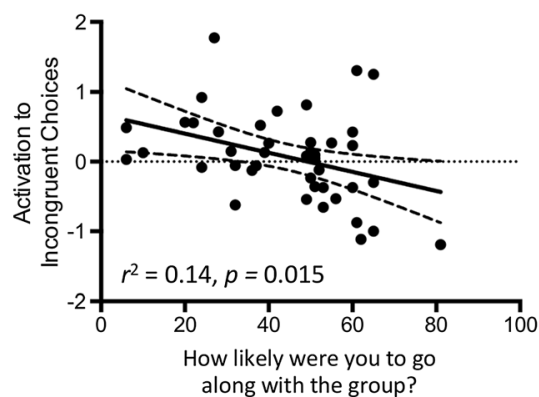

\section{ROI-Based Comparison Between Groups}

Right Caudate

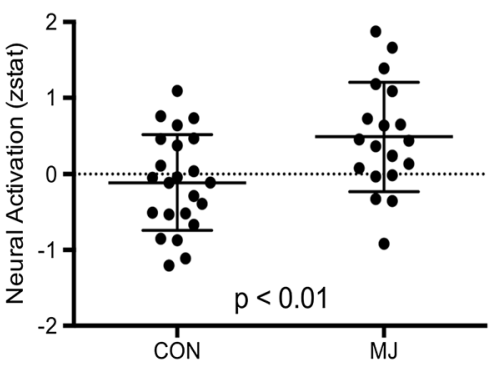

Right Nucleus Accumbens

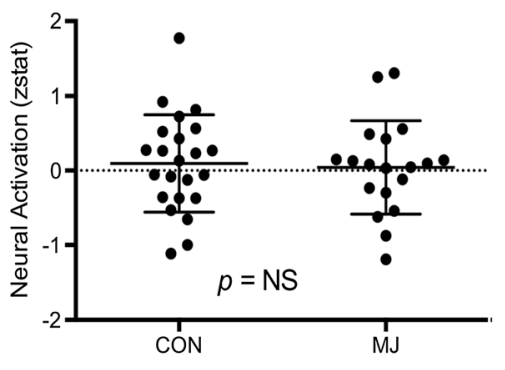

Fig. 4 Associations between self-reported conformity and brain activation. (a) Depiction of the anatomical masks used in the ROI analysis. (b) Peer conformity scores on the MISS correlated with activation in the right caudate in response to viewing peer information (top). Self-reported likeliness to go along with group influence also correlated with deactivation of the right NAc in response to making incongruent choices (bottom). (C) MJ users showed significantly greater activation than did controls in the right caudate when viewing group information (top); there was no difference between groups in activation of the NAc (bottom) 
responses on the task $\left(r^{2}=.45, p=.002\right)$. There was also a significant correlation across groups, so that those who reported that they were most likely to go along with group influence showed the greatest NAc deactivation when making incongruent choices, particularly on the right $\left(r^{2}=.14, p=.015\right)$ (Fig. 4b, bottom). This correlation indicated that those who reported they were most likely to go along with the group had the greatest NAc deactivation when making the choice to go against the group instead. These questionnaire ratings did not correlate with caudate activation. An ROI-based comparison between groups did not show significant differences in NAc activation (Fig. 4c, bottom). An additional whole-brain analysis in which questionnaire scores were regressed onto the whole-brain random-effects analysis did not reveal any significant or subthreshold clusters. We observed no significant group differences in NAc activation.

\section{Correlations between reaction time and brain activation to} the "choice" event during incongruent choices To test the hypothesis that the increased reaction times in the MJ group were related to increased effortful processing, we ran an additional analysis in which reaction times were regressed onto the whole-brain model for the condition of incongruent choices (Table 3). We found that both groups showed significant correlations between reaction times and activation, particularly in frontal regions such as bilateral DLPFC (in CON) and IFG (in MJ), and well as in parietal and occipital regions (Fig. 5). In a direct comparison in which we tested whether the linear relationship between Event 3 (Incongruent Choice) and reaction times differed between groups, we found a significant interaction in the left IFG, as well as in other frontal, parietal, and occipital regions. This interaction indicated that the slope of the correlation between activation and reaction time within the MJ group was steeper than that in the CON group. Reaction times did not correlate with either self-reported peer conformity or brain activation in the caudate.

\section{Discussion}

Though decades of research have supported the importance of social influence in the initiation and maintenance of drug use, the literature on the neural correlates of social influence in the context of substance use is sparse. Here we report results from a novel experimental approach to evaluating the effects of social influence on both behavioral susceptibility and neural activation to influence. Both MJ users and controls were more likely to follow than to oppose group recommendations, at the expense of accuracy, but only Group MJ showed choice reaction times slowing when going against the group, reflected in increased IFG activation correlating with reaction times, suggesting more effortful/contemplative processing. The MJ group also exhibited greater caudate activation than controls when presented with peer information/social influence. The

Table 3 Brain activation to Event 3, Choice (incongruent responses), correlated with reaction time

\begin{tabular}{|c|c|c|c|c|c|c|c|}
\hline Area & HEM & Region & $x$ & $y$ & $z$ & $Z$ Stat & VOL \\
\hline \multicolumn{8}{|c|}{ Activation in CONTROLS } \\
\hline \multirow[t]{2}{*}{ Frontal } & $\mathrm{L}$ & DLPFC & -50 & 2 & 44 & 3.98 & 1,718 \\
\hline & $\mathrm{R}$ & DLPFC & 48 & 6 & 36 & 3.4 & 513 \\
\hline Parietal & $\mathrm{L}$ & Superior parietal lobule & -30 & -44 & 48 & 4.1 & 2,341 \\
\hline Occipital & $\mathrm{R}$ & Occipital cortex & 28 & -76 & 30 & 3.38 & 1,200 \\
\hline \multicolumn{8}{|c|}{ Activation in MJ Participants } \\
\hline \multirow[t]{4}{*}{ Frontal } & $\mathrm{L} / \mathrm{R}$ & Superior frontal gyrus & 4 & 50 & 36 & 3.61 & 1,496 \\
\hline & $\mathrm{L}$ & Inferior frontal gyrus & -38 & 22 & 18 & 3.56 & 631 \\
\hline & $\mathrm{R}$ & Inferior frontal gyrus & 52 & 22 & 14 & 3.42 & 393 \\
\hline & $\mathrm{R}$ & Orbitofrontal cortex & 46 & 30 & -8 & 3.45 & 457 \\
\hline Parietal & $\mathrm{L} / \mathrm{R}$ & Precuneus & 4 & -58 & 24 & 4.04 & 618 \\
\hline \multicolumn{8}{|c|}{ MJ $>$ CONTROLS } \\
\hline \multirow[t]{2}{*}{ Frontal } & $\mathrm{L}$ & Inferior frontal gyrus & -42 & 28 & 14 & 3.37 & 532 \\
\hline & $\mathrm{L}$ & Superior frontal gyrus & -14 & -4 & 76 & 3.43 & 399 \\
\hline Parietal & $\mathrm{L}$ & Supramarginal gyrus & -36 & -46 & 42 & 3.57 & 1,271 \\
\hline Occipital & $\mathrm{L}$ & Lateral occipital cortex & -50 & -68 & 16 & 3.49 & 541 \\
\hline Subcortical & $\mathrm{R}$ & Insula & 32 & 8 & 12 & 3.31 & 518 \\
\hline
\end{tabular}

$Z$ (Gaussianized T/F) statistic images were thresholded using clusters determined by $Z>2.3$ and a (corrected) whole-brain cluster significance threshold of $p<.05$. HEM represents the hemisphere. Coordinates are in MNI space. VOL $=$ volume, in number of voxels $\left(2 \times 2 \times 2 \mathrm{~mm}^{3}\right)$. 

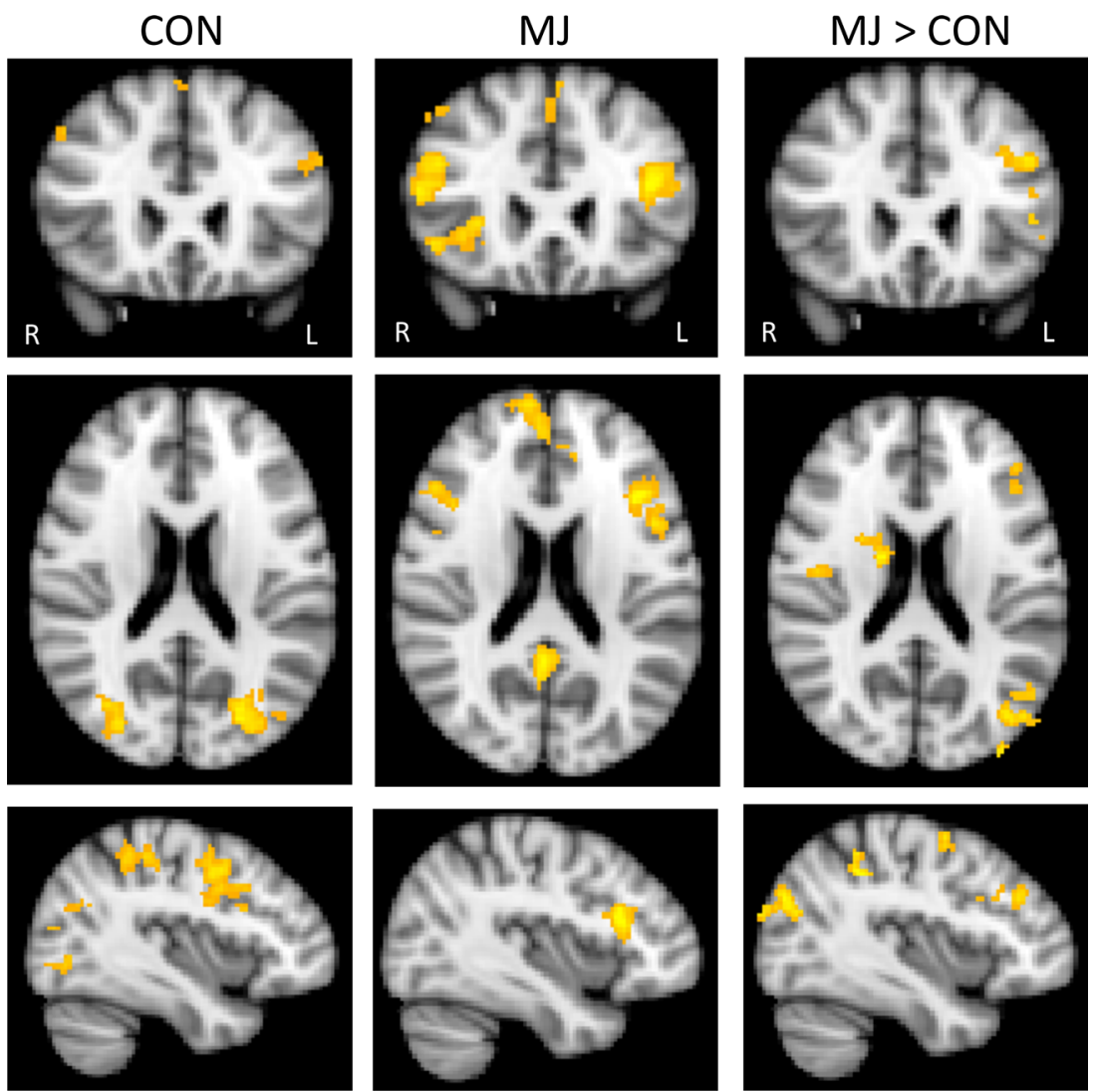

Fig. 5 Brain activation to Event 3 (Choice) in Groups MJ and CON, correlated with reaction times. Both groups showed significant correlations between reaction times and activation, particularly in frontal regions such as bilateral DLPFC (in CON) and the IFG (in MJ), and well as in parietal and occipital regions. In brain regions such as the left IFG, the correlation between activation and reaction time was stronger within the MJ than within the CON group. All clusters shown were thresholded using clusters determined by $Z>2.3$ and a (corrected) whole-brain cluster significance threshold of $p<.05$

for decision making can be seen as the time from deliberation to choice selection, and deliberation usually takes a longer time when a decision is harder (Lo \& Wang, 2006). Previous work using a similar social decision-making task showed that reaction times were slowest for trials in which the social influence was "incongruent" with the expected choice, and fastest for "congruent" trials (Gilman, Treadway, Curran, Calderon, \& Evins, 2015). Critically, in this previously published work, individuals who showed a greater bias toward conformity also showed larger reaction time slowing effects during incongruent trials.

There are several potential explanations for the longer reaction times in the MJ group during incongruent trials. The differences in reaction times with an absence of overt choice differences may indicate that although the MJ group were capable of coming to the same decisions as the control group in a laboratory environment, it may have been more effortful for young adult MJ users to oppose group influence. Indeed, prior studies in rodents have demonstrated that various drugs of abuse can impact the ability to exercise cognitive control when making decisions (e.g., Cocker, Hosking, Benoit, \& Winstanley, 2012). This has been the first study to our 
knowledge to investigate this effect in humans with social influence and in the context of MJ use. Decision speed is modulated by cognitive variables such as attention and working memory (Ester, Ho, Brown, \& Serences, 2014; Nunez, Srinivasan, \& Vandekerckhove, 2015; Whitney, Rinehart, \& Hinson, 2008), and it has been widely demonstrated that MJ use is associated with these domain-specific deficits (Colizzi et al., 2015; Jacobus et al., 2015; Price et al., 2015). An alternative explanation is that the longer reaction times during the incongruent trials could indicate that the MJ users experienced impaired cognition associated with identifying and/or resolving information conflicts. Since all participants were less confident during incongruent trials, it is likely that all participants were engaging in cognitive processing of identifying error detection/conflicting information during these trials-skills that rely largely on the function of the caudate (Davidson et al., 2004; Delgado, Miller, Inati, \& Phelps, 2005; Haruno \& Kawato, 2006; O'Doherty, 2004; O'Doherty et al., 2004). It is therefore possible that the MJ users had greater difficulty coming to a decision during these conflict trials than did control participants. In real-life situations, this "extra" effort required to make decisions that go against influence could potentially confer a greater risk of suboptimal decision making. Future studies will need to examine whether the tendency to slower processing when making decisions that go against group influence confers vulnerability to initiate and continue using MJ, as well as to engage in other risk behaviors. The neuroimaging results showing an increased correlation between reaction time and activation of the IFG in the MJ relative to the CON group supports the hypothesis that resisting peer influence may be more effortful in the MJ group (Swick et al., 2008).

In addition to reaction time differences, we also found group differences in brain activation during the presentation of social influence. MJ users but not controls showed activation bilaterally in the caudate. The dorsal striatum, including the caudate and the putamen, has a prominent role in decision making. Although the ventral striatum has been implicated in passive receipt of reward (e.g., drug reward: Gilman, Ramchandani, Crouss, \& Hommer, 2012; Gilman, Ramchandani, Davis, Bjork, \& Hommer, 2008; and monetary reward: O'Doherty et al., 2004), the dorsal striatum is thought to mediate important aspects of decision making related to goal-directed action, and to underlie the selection of actions on the basis of their expected reward value. Studies have suggested that the caudate nucleus, in particular, is involved in coding reward prediction errors during goal-directed behavior (Davidson et al., 2004; Delgado et al., 2005; Haruno \& Kawato, 2006; O'Doherty, 2004; O'Doherty et al., 2004), and even more specifically, behavior regarding complex social issues such as social cooperation (Rilling et al., 2002), revenge (de Quervain et al., 2004), and the acquisition of social reputations (King-Casas et al., 2005). In the present study, their hyperactivation of the caudate during the receipt of social information could indicate that perhaps the MJ group was particularly responsive to social information.

The data from this study support the notion that the caudate is important for social decision making and may be sensitive to individual differences. Across groups, activation of the caudate positively correlated with self-reported peer conformity on the MISS, indicating that activation of the caudate is associated with social reward, particularly in those who value group conformity. Prior studies have suggested that the valuation of social stimuli relies on mesocorticolimbic circuitry that largely overlaps with that related to other reinforcers (Jones et al., 2011; Klucharev et al., 2009). Social conformity may serve as an additional value signal that is incorporated with other standard reinforcement parameters (e.g., effort, reward magnitude, and probability) to derive a single subjective value for a given option (Kable \& Glimcher, 2009; Sescousse, Li, \& Dreher, 2015).

Though the right caudate was the only region that showed significantly greater activation in the MJ than in the $\mathrm{CON}$ group to peer influence after whole-brain correction, it is important to point out that several other brain regions were more highly activated in the MJ group, including the IFG, orbitofrontal cortex, and anterior cingulate. These regions, particularly the IFG, are important in the cognitive control of decision making, specifically in inhibitory control and task switching (Aron, Robbins, \& Poldrack, 2004), domains that may be impacted by MJ use (see, e.g., Gruber \& Yurgelun-Todd, 2005). Longer reaction times in the MJ group than among controls, as well as the observation that the MJ group demonstrated a stronger correlation between reaction time and activation of the IFG, could indicate that the MJ users experienced more difficulty with error monitoring/cognitive control during the task. Though the differences in activation of these regions did not survive whole-brain correction in the present study, they nonetheless could be followed up in future studies with larger sample sizes.

We assessed participants' self-reported propensities to follow group decisions and found a correlation, such that those who reported high susceptibility to influence (e.g., who were likely to follow group decisions) had greater deactivation of the NAc in response to incongruent choices. These results are interesting in light of results from previous studies (Klucharev et al., 2009; Zaki et al., 2011) showing that agreeing with peers increased activity in the NAc, whereas disagreeing decreased NAc activity. In a landmark study of social influence in which participants were asked to rate the attractiveness of faces before and after learning about how peers had rated the faces, deactivation of the NAc during a conflict with group opinion predicted conformity on future trials (Klucharev et al., 2009). We found that this decreased NAc activity to disagreeing with the group was strongest among those who reported that they were likely to follow the group. Though there were differences in the temporal 
sequences of decision making between the Klucharev paradigm, in which NAc deactivation occurred in response to finding out that peer opinion conflicted with one's already submitted choice, and the present study, in which participants saw peer judgments before making their choices, the present findings replicate research showing that activation of the NAc is an important signature of conformity versus independence, and may be sensitive to individual differences in peer susceptibility among both MJ users and nonusers. This study also suggests that the NAc may be sensitive to making/implementing choices to conform, whereas the caudate may be more sensitive to the receipt of differentially salient peer information. The implication of this distinction may be that, whereas peer information itself can activate social goals and relevant behavior, actual choice may be more related to hedonic value.

There are several caveats to interpreting this study. First, though MJ users and the CON group showed differences in activation of the caudate, this brain difference occurred in the absence of a behavioral difference in susceptibility to influence during the social influence task. Several explanations could account for why brain-based differences would be observed despite a lack of differences in task performance (for a commentary, see Gilman, Bjork, \& Wilens, 2015), but most notably, it is important to acknowledge that scanner-based experimental psychology tasks represent grossly simplified traces of complex real-life behaviors. Our task investigates social influences on decision making during a low-arousal task in which the outcome (comparing the relative lengths of lines) is not particularly meaningful to the participants. Social influences that occur in the context of drug use are likely to have high arousal, be personally meaningful, and require complex balancing of the costs and benefits of following or dissenting from peer opinion. The difference in brain signals could indicate that in the artificial scanner environment, MJ users were able to exhibit normative decision-making patterns, but may be more challenged than healthy controls in real-life settings involving peer influence. Future studies may employ tasks more relevant to drugseeking and drug-using behavior, such as risk-taking and motivation tasks, to further probe whether more effortful tasks would reveal behavioral differences as well as allow us to better understand the predictive utility of slowed decision making in understanding real-world functional outcomes.

A further limitation of this study was that because of the large number of experimental conditions included in the task to create a balanced design, the number of trials per condition was relatively low (44 trials total, with 28 active "influence" trials), and this may not have been optimal for revealing statistically robust effects. Future studies might include either more task runs or fewer conditions, in order to maximize statistical effects and minimize the chance of a Type II error.

An additional limitation is that the criteria for eligibility in the MJ group required only weekly or more frequent use. Though weekly or more frequent use is indicative of a regular pattern of use, studies of heavier users might better capture brain-based correlates of MJ use. Furthermore, though the focus of the present study was on MJ use specifically, young adults using other substances, such as alcohol or nicotine, may show similar brain-based hyperactivity to peer influence. Though alcohol use did not contribute to the results reported in the present study, all of the participants were fairly light drinkers. Future studies could recruit heavy drinkers/cigarette smokers to test whether these individuals also show hypersensitivity in the caudate to peer information, or whether this is an effect of MJ specifically. An additional avenue for research would be to examine the role of educational attainment in susceptibility to influence; in the present study, most participants were currently college students or recent college graduates, but it is possible that in addition to age, level of education could influence susceptibility. Future studies could also examine how different motivations for drug use (e.g., coping, social engagement, etc.) may contribute to different patterns of brain activity underlying social influence and drug use.

Finally, this study cannot detect whether increased neural activation to influence is a cause or an effect of drug use. Several possible explanations could account for the relationship between MJ use and susceptibility to social influence: (1) Increased susceptibility to social influence may be a trait that reflects a preexisting risk for initiation of MJ use; (2) susceptibility to social influence may have developed as a result of MJ exposure, due to disruption to the neurodevelopmental processes underlying social processing; (3) a third variable, such as striatal reactivity, may be responsible for giving rise to both MJ use and susceptibility to social influence; or (4) some combination of the explanations above may be responsible for the relationship between MJ use and susceptibility to social influence. Although the present study cannot differentiate among these explanations, it may help researchers develop hypotheses for future work addressing causality.

Identifying brain regions that differ in response to social influence may influence treatments such as lifestyle management, which could encourage MJ users to find alternative positive reinforcement in the natural environment. Many studies have shown that social network support is a critical factor in promoting healthier lifestyle behaviors, in addition to ongoing abstinence (e.g., Bond, Kaskutas, \& Weisner, 2003; Kaskutas, Bond, \& Humphreys, 2002). If marijuana users are indeed more susceptible to peer influence, future studies could investigate whether positive peer influences may be particularly effective as an intervention in this group.

Author note This work was supported by Grants NIDA K01 DA034093 (J.M.G.) and NIDA K24 DA030443 (A.E.E.). These funding sources had no role in the study design, collection, analysis or interpretation of the data, writing the manuscript, or the decision to submit the manuscript for publication. 


\section{References}

Acheson, A., Ray, K. L., Hines, C. S., Li, K., Dawes, M. A., Mathias, C. W., ... Laird, A. R. (2015). Functional activation and effective connectivity differences in adolescent marijuana users performing a simulated gambling task. Journal of Addiction, 2015, 783106. doi: $10.1155 / 2015 / 783106$

Ames, S. L., Grenard, J. L., Stacy, A. W., Xiao, L., He, Q., Wong, S. W., ... Bechara, A. (2013). Functional imaging of implicit marijuana associations during performance on an Implicit Association Test (IAT). Behavioural Brain Research, 256, 494-502. doi:10.1016/j. bbr.2013.09.013

Aron, A. R., Robbins, T. W., \& Poldrack, R. A. (2004). Inhibition and the right inferior frontal cortex. Trends in Cognitive Sciences, 8, 170-177. doi:10.1016/j.tics.2004.02.010

Asch, S. E. (1951). Effects of group pressure upon the modification distortion of judgments. In H. Guetzkow (Ed.), Groups, leadership, and men (pp. 177-190). Pittsburgh: Carnegie Press.

Asch, S. E. (1952). Social psychology. Englewood Ciffs: Prentice Hall.

Asch, S. E. (1956). Studies of independence and conformity: I. A minority of one against a unanimous majority. Psychological Monographs: General and Applied, 70(9, Whole No. 416), 170.

Bergé, D., Mané, A., Salgado, P., Cortizo, R., Garnier, C., Gomez, L., ... Pérez, V. (2016). Predictors of relapse and functioning in first-episode psychosis: A two-year follow-up study. Psychiatric Services, 67, 227-233. doi:10.1176/appi.ps.201400316

Berns, G. S., Capra, C. M., Moore, S., \& Noussair, C. (2010). Neural mechanisms of the influence of popularity on adolescent ratings of music. NeuroImage, 49, 2687-2696. doi:10.1016/j.neuroimage. 2009.10.070

Berns, G. S., Chappelow, J., Zink, C. F., Pagnoni, G., MartinSkurski, M. E., \& Richards, J. (2005). Neurobiological correlates of social conformity and independence during mental rotation. Biological Psychiatry, 58, 245-253. doi:10.1016/j. biopsych.2005.04.012

Bohbot, V. D., Del Balso, D., Conrad, K., Konishi, K., \& Leyton, M. (2013). Caudate nucleus-dependent navigational strategies are associated with increased use of addictive drugs. Hippocampus, 23, 973-984. doi:10.1002/hipo.22187

Bond, J., Kaskutas, L. A., \& Weisner, C. (2003). The persistent influence of social networks and alcoholics anonymous on abstinence. Journal of Studies on Alcohol, 64, 579-588.

Bossong, M. G., van Berckel, B. N., Boellaard, R., Zuurman, L., Schuit, R. C., Windhorst, A. D., ... Kahn, R. S. (2009). Delta 9tetrahydrocannabinol induces dopamine release in the human striatum. Neuropsychopharmacology, 34, 759-766. doi:10. 1038/npp.2008.138

Bowman, F. D., Guo, Y., \& Derado, G. (2007). Statistical approaches to functional neuroimaging data. Neuroimaging Clinics of North America, 17, 441-458. doi:10.1016/j.nic.2007.09.002

Chambers, R. A., Taylor, J. R., \& Potenza, M. N. (2003). Developmental neurocircuitry of motivation in adolescence: A critical period of addiction vulnerability. American Journal of Psychiatry, 160, 1041-1052. doi:10.1176/appi.ajp.160.6.1041

Chau, W., \& McIntosh, A. R. (2005). The Talairach coordinate of a point in the MNI space: How to interpret it. NeuroImage, 25, 408-416. doi:10.1016/j.neuroimage.2004.12.007

Chein, J., Albert, D., O’Brien, L., Uckert, K., \& Steinberg, L. (2011). Peers increase adolescent risk taking by enhancing activity in the brain's reward circuitry. Developmental Science, 14, F1-10. doi:10.1111/j.1467-7687.2010.01035.x

Clayton, R. R., \& Lacy, W. B. (1982). Interpersonal influences on male drug use and drug use intentions. International Journal of the Addictions, 17, 655-666.
Cocker, P. J., Hosking, J. G., Benoit, J., \& Winstanley, C. A. (2012). Sensitivity to cognitive effort mediates psychostimulant effects on a novel rodent cost/benefit decision-making task. Neuropsychopharmacology, 37, 1825-1837. doi:10.1038/npp. 2012.30

Colizzi, M., Fazio, L., Ferranti, L., Porcelli, A., Masellis, R., Marvulli, D., ... Bertolino, A. (2015). Functional genetic variation of the cannabinoid receptor 1 and cannabis use interact on prefrontal connectivity and related working memory behavior. Neuropsychopharmacology, 40, 640-649. doi:10.1038/npp. 2014.213

Davidson, M. C., Horvitz, J. C., Tottenham, N., Fossella, J. A., Watts, R., Ulug, A. M., \& Casey, B. J. (2004). Differential cingulate and caudate activation following unexpected nonrewarding stimuli. NeuroImage, 23, 1039-1045. doi:10.1016/j.neuroimage.2004.07.049

de Quervain, D. J., Fischbacher, U., Treyer, V., Schellhammer, M., Schnyder, U., Buck, A., \& Fehr, E. (2004). The neural basis of altruistic punishment. Science, 305, 1254-1258. doi:10.1126/ science. 1100735

Delgado, M. R., Miller, M. M., Inati, S., \& Phelps, E. A. (2005). An fMRI study of reward-related probability learning. NeuroImage, 24, 862-873. doi:10.1016/j.neuroimage.2004. 10.002

Downer, E., Boland, B., Fogarty, M., \& Campbell, V. (2001). Delta 9tetrahydrocannabinol induces the apoptotic pathway in cultured cortical neurones via activation of the CB1 receptor. NeuroReport, 12, 3973-3978.

Epstein, M., Hill, K. G., Nevell, A. M., Guttmannova, K., Bailey, J. A., Abbott, R. D., ... Hawkins, J. D. (2015). Trajectories of marijuana use from adolescence into adulthood: Environmental and individual correlates. Developmental Psychology, 51, 1650-1663. doi:10. 1037/dev0000054

Ester, E. F., Ho, T. C., Brown, S. D., \& Serences, J. T. (2014). Variability in visual working memory ability limits the efficiency of perceptual decision making. Journal of Vision, 14(4), 2. doi: $10.1167 / 14.4 .2$

First, M. B., Spitzer, R. L., Miriam, G., \& Williams, J. B. W. (2002). Structured Clinical Interview for DSM-IV-TR Axis I disorders, research version, patient edition (SCID-I/P). New York: New York State Psychiatric Institute, Biometrics Research.

Gardner, M., \& Steinberg, L. (2005). Peer influence on risk taking, risk preference, and risky decision making in adolescence and adulthood: an experimental study. Developmental Psychology, 41, 625635. doi:10.1037/0012-1649.41.4.625

Gasic, G. P., Smoller, J. W., Perlis, R. H., Sun, M., Lee, S., Kim, B. W., ... Breiter, H. C. (2009). BDNF, relative preference, and reward circuitry responses to emotional communication. American Journal of Medical Genetics, 150B, 762-781. doi:10.1002/ajmg.b.30944

Gilman, J. M., Bjork, J. M., \& Wilens, T. E. (2015). Brain signaling in psychiatric disorders: What can they tell us in the absence of behavioral differences? Journal of Behavioral and Brain Science, 05, 333-337. doi:10.4236/jbbs.2015.58033

Gilman, J. M., Kuster, J. K., Lee, S., Lee, M. J., Kim, B. W., Makris, N., ... Breiter, H. C. (2014). Cannabis use is quantitatively associated with nucleus accumbens and amygdala abnormalities in young adult recreational users. Journal of Neuroscience, 34, 5529-5538. doi:10. 1523/JNEUROSCI.4745-13.2014

Gilman, J. M., Lee, S., Kuster, J. K., Lee, M. J., Kim, B. W., van der Kouwe, A., ... Breiter, H. C. (2016). Variable activation in striatal subregions across components of a social influence task in young adult cannabis users. Brain and Behavior, O(0), e00459. doi:10. 1002/brb3.459

Gilman, J. M., Ramchandani, V. A., Crouss, T., \& Hommer, D. W. (2012). Subjective and neural responses to intravenous alcohol in young adults with light and heavy drinking patterns. 
Neuropsychopharmacology, 37, 467-477. doi:10.1038/npp.2011. 206

Gilman, J. M., Ramchandani, V. A., Davis, M. B., Bjork, J. M., \& Hommer, D. W. (2008). Why we like to drink: A functional magnetic resonance imaging study of the rewarding and anxiolytic effects of alcohol. Journal of Neuroscience, 28, 4583-4591. doi:10. 1523/JNEUROSCI.0086-08.2008

Gilman, J. M., Treadway, M. T., Curran, M. T., Calderon, V., \& Evins, A. E. (2015). Effect of social influence on effort-allocation for monetary rewards. PLoS ONE, 10, e0126656. doi:10.1371/journal.pone. 0126656

Goodman, J., \& Packard, M. G. (2015). The influence of cannabinoids on learning and memory processes of the dorsal striatum. Neurobiology of Learning and Memory, 125, 1-14. doi:10.1016/ j.nlm.2015.06.008

Gosling, S. D., Rentfrow, P. J., \& Swann, W. B., Jr. (2003). A very brief measure of the Big Five personality domains. Journal of Research in Personality, 37, 504-528.

Green, K. M., Musci, R. J., Johnson, R. M., Matson, P. A., Reboussin, B. A., \& Ialongo, N. S. (2015). Outcomes associated with adolescent marijuana and alcohol use among urban young adults: A prospective study. Addictive Behaviors, 53, 155-160. doi:10.1016/j.addbeh. 2015.10.014

Gruber, S. A., \& Yurgelun-Todd, D. A. (2005). Neuroimaging of marijuana smokers during inhibitory processing: A pilot investigation. Cognitive Brain Research, 23, 107-118. doi:10.1016/j.cogbrainres. 2005.02.016

Guyer, A. E., Benson, B., Choate, V. R., Bar-Haim, Y., Perez-Edgar, K., Jarcho, J. M., ... Nelson, E. E. (2014). Lasting associations between early-childhood temperament and late-adolescent reward-circuitry response to peer feedback. Developmental Psychopathology, 26, 229-243. doi:10.1017/S0954579413000941

Hall, W., \& Degenhardt, L. (2009). Adverse health effects of non-medical cannabis use. Lancet, 374, 1383-1391. doi:10.1016/S01406736(09)61037-0

Hartwell, K. J., Back, S. E., McRae-Clark, A. L., Shaftman, S. R., \& Brady, K. T. (2012). Motives for using: A comparison of prescription opioid, marijuana and cocaine dependent individuals. Addictive Behaviors, 37, 373-378. doi:10.1016/j.addbeh.2011.11.014

Haruno, M., \& Kawato, M. (2006). Different neural correlates of reward expectation and reward expectation error in the putamen and caudate nucleus during stimulus-action-reward association learning. Journal of Neurophysiology, 95, 948-959. doi:10.1152/jn.00382. 2005

Heath, R. G., Fitzjarrell, A. T., Fontana, C. J., \& Garey, R. E. (1980). Cannabis sativa: Effects on brain function and ultrastructure in rhesus monkeys. Biological Psychiatry, 15, 657-690.

Henry, J. A., Oldfield, W. L., \& Kon, O. M. (2003). Comparing cannabis with tobacco. BMJ, 326, 942-943. doi:10.1136/bmj. 326.7396 .942

Jacobus, J., Squeglia, L. M., Infante, M. A., Castro, N., Brumback, T., Meruelo, A. D., \& Tapert, S. F. (2015). Neuropsychological performance in adolescent marijuana users with co-occurring alcohol use: A three-year longitudinal study. Neuropsychology, 29, 829-843. doi:10.1037/neu0000203

Jenkinson, M., \& Smith, S. (2001). A global optimisation method for robust affine registration of brain images. Medical Image Analysis, $5,143-156$

Jones, R. M., Somerville, L. H., Li, J., Ruberry, E. J., Libby, V., Glover, G., ... Casey, B. J. (2011). Behavioral and neural properties of social reinforcement learning. Journal of Neuroscience, 31, 13039-13045. doi:10.1523/JNEUROSCI.2972-11.2011

Kable, J. W., \& Glimcher, P. W. (2009). The neurobiology of decision: Consensus and controversy. Neuron, 63, 733-745. doi:10.1016/j. neuron.2009.09.003
Kaskutas, L. A., Bond, J., \& Humphreys, K. (2002). Social networks as mediators of the effect of Alcoholics Anonymous. Addiction, 97, 891-900.

Khavari, K. A. (1993). Interpersonal influences in college students' initial use of alcohol and drugs - The role of friends, self, parents, doctors, and dealers. International Journal of the Addictions, 28, 377-388.

King-Casas, B., Tomlin, D., Anen, C., Camerer, C. F., Quartz, S. R., \& Montague, P. R. (2005). Getting to know you: reputation and trust in a two-person economic exchange. Science, 308, 78-83. doi:10. 1126/science. 1108062

Klucharev, V., Hytonen, K., Rijpkema, M., Smidts, A., \& Fernandez, G. (2009). Reinforcement learning signal predicts social conformity Neuron, 61, 140-151. doi:10.1016/j.neuron.2008.11.027

Knoll, L. J., Magis-Weinberg, L., Speekenbrink, M., \& Blakemore, S. J. (2015). Social influence on risk perception during adolescence. Psychological Science, 26, 583-592. doi:10.1177/ 0956797615569578

Kolb, B., Gorny, G., Limebeer, C. L., \& Parker, L. A. (2006). Chronic treatment with Delta-9-tetrahydrocannabinol alters the structure of neurons in the nucleus accumbens shell and medial prefrontal cortex of rats. Synapse, 60, 429-436. doi:10.1002/syn.20313

Kotov, R., Bellman, S. B., \& Watson, D. B. (2004). Multidimensional Iowa Suggestibility Scale (MISS) Brief Manual. Stoneybrook Medicine. Retrieved June, 2014, from medicine. stonybrookmedicine.edu/system/files/MISSBriefManual.pdf

Lagerberg, T. V., Icick, R., Andreassen, O. A., Ringen, P. A., Etain, B., Aas, M., ... Bellivier, F. (2015). Cannabis use disorder is associated with greater illness severity in tobacco smoking patients with bipolar disorder. Journal of Affective Disorders, 190, 286-293. doi:10. 1016/j.jad.2015.10.023

Lawston, J., Borella, A., Robinson, J. K., \& Whitaker-Azmitia, P. M. (2000). Changes in hippocampal morphology following chronic treatment with the synthetic cannabinoid WIN 55,212-2. Brain Research, 877, 407-410.

Lo, C. C., \& Wang, X. J. (2006). Cortico-basal ganglia circuit mechanism for a decision threshold in reaction time tasks. Nature Neuroscience, 9, 956-963. doi:10.1038/nn1722

Lorenzetti, V., Solowij, N., Fornito, A., Lubman, D. I., \& Yucel, M. (2014). The association between regular cannabis exposure and alterations of human brain morphology: An updated review of the literature. Current Pharmaceutical Design, 20, 2138-2167.

Mason, M., Dyer, R., \& Norton, M. I. (2009). Neural mechanisms of social influence. Organizational Behavior and Human Decision Processes, 110, 152-159.

Masten, C. L., Eisenberger, N. I., Borofsky, L. A., Pfeifer, J. H., McNealy, K., Mazziotta, J. C., \& Dapretto, M. (2009). Neural correlates of social exclusion during adolescence: Understanding the distress of peer rejection. Social Cognitive and Affective Neuroscience, 4, 143-157. doi:10.1093/scan/nsp007

Meier, M. H., Hill, M. L., Small, P. J., \& Luthar, S. S. (2015). Associations of adolescent cannabis use with academic performance and mental health: A longitudinal study of upper middle class youth. Drug and Alcohol Dependence, 156, 207-212. doi:10.1016/j. drugalcdep.2015.09.010

Minear, M., \& Park, D. C. (2004). A lifespan database of adult facial stimuli. Behavior Research Methods, Instruments, \& Computers, 36, 630-633. doi:10.3758/BF03206543

Nestler, E. J., \& Carlezon, W. A., Jr. (2006). The mesolimbic dopamine reward circuit in depression. Biological Psychiatry, 59, 1151-1159. doi:10.1016/j.biopsych.2005.09.018

Nunez, M. D., Srinivasan, R., \& Vandekerckhove, J. (2015). Individual differences in attention influence perceptual decision making. Frontiers in Psychology, 8, 18. doi:10.3389/fpsyg. 2015.00018 
O’Doherty, J., Dayan, P., Schultz, J., Deichmann, R., Friston, K., \& Dolan, R. J. (2004). Dissociable roles of ventral and dorsal striatum in instrumental conditioning. Science, 304, 452-454. doi:10.1126/ science. 1094285

O'Doherty, J. P. (2004). Reward representations and reward-related learning in the human brain: Insights from neuroimaging. Current Opinion in Neurobiology, 14, 769-776. doi:10.1016/j.conb.2004. 10.016

Perlis, R. H., Holt, D. J., Smoller, J. W., Blood, A. J., Lee, S., Kim, B. W., ... Breiter, H. C. (2008). Association of a polymorphism near CREB1 with differential aversion processing in the insula of healthy participants. Archives of General Psychiatry, 65, 882-892. doi:10. 1001/archgenpsychiatry.2008.3

Pfeifer, J. H., Masten, C. L., Moore, W. E., III, Oswald, T. M., Mazziotta, J. C., Iacoboni, M., \& Dapretto, M. (2011). Entering adolescence: Resistance to peer influence, risky behavior, and neural changes in emotion reactivity. Neuron, 69, 1029-1036. doi:10.1016/j.neuron. 2011.02.019

Polonec, L. D., Major, A. M., \& Atwood, L. E. (2006). Evaluating the believability and effectiveness of the social norms message "most students drink 0 to 4 drinks when they party.". Health Communication, 20, 23-34. doi:10.1207/ s15327027hc2001 3

Price, J. S., McQueeny, T., Shollenbarger, S., Browning, E. L., Wieser, J., \& Lisdahl, K. M. (2015). Effects of marijuana use on prefrontal and parietal volumes and cognition in emerging adults. Psychopharmacology, 232, 2939-2950. doi:10.1007/s00213-0153931-0

Rilling, J., Gutman, D., Zeh, T., Pagnoni, G., Berns, G., \& Kilts, C. (2002). A neural basis for social cooperation. Neuron, 35, 395-405.

Sanfey, A. G., Rilling, J. K., Aronson, J. A., Nystrom, L. E., \& Cohen, J. D. (2003). The neural basis of economic decision-making in the Ultimatum Game. Science, 300, 1755-1758. doi:10.1126/science. 1082976

Scallet, A. C., Uemura, E., Andrews, A., Ali, S. F., McMillan, D. E., Paule, M. G., ... Slikker, W., Jr. (1987). Morphometric studies of the rat hippocampus following chronic delta-9-tetrahydrocannabinol (THC). Brain Research, 436, 193-198.

Sescousse, G., Li, Y., \& Dreher, J. C. (2015). A common currency for the computation of motivational values in the human striatum. Social Cognitive and Affective Neuroscience, 10, 467-473. doi:10.1093/ scan/nsu074

Silins, E., Fergusson, D. M., Patton, G. C., Horwood, L. J., Olsson, C. A., Hutchinson, D. M., ... Mattick, R. P. (2015). Adolescent substance use and educational attainment: An integrative data analysis comparing cannabis and alcohol from three Australasian cohorts. Drug and Alcohol Dependence, 156, 90-96. doi:10.1016/j.drugalcdep. 2015.08.034

Smith, A. R., Steinberg, L., Strang, N., \& Chein, J. (2015). Age differences in the impact of peers on adolescents' and adults' neural response to reward. Developmental Cognitive Neuroscience, 11, 7582. doi:10.1016/j.den.2014.08.010

Smith, S. M. (2002). Fast robust automated brain extraction. Human Brain Mapping, 17, 143-155. doi:10.1002/hbm.10062

Sobell, M. B., Sobell, L. C., Klajner, F., Pavan, D., \& Basian, E. (1986). The reliability of a timeline method for assessing normal drinker college students' recent drinking history: Utility for alcohol research. Addictive Behaviors, 11, 149-161.

Solowij, N., \& Battisti, R. (2008). The chronic effects of cannabis on memory in humans: A review. Current Drug Abuse Reviews, 1, 81-98.
Solowij, N., Stephens, R., Roffman, R. A., \& Babor, T. (2002). Does marijuana use cause long-term cognitive deficits? JAMA, 287, 2653-2654.

Substance Abuse and Mental Health Services Administration (2011). Results from the 2011 National Survey on Drug Use and Health: Summary of National Findings, NSDUH Series H-44, HHS Publication No. (SMA) 12-4713. Rockville, MD: Substance Abuse and Mental Health Services Administration, 2012.

Swick, D., Ashley, V., \& Turken, A. U. (2008). Left inferior frontal gyrus is critical for response inhibition. $B M C$ Neuroscience, 9, 102. doi:10.1186/1471-2202-9-102

Telzer, E. H., Fuligni, A. J., Lieberman, M. D., Miernicki, M. E., \& Galvan, A. (2015). The quality of adolescents' peer relationships modulates neural sensitivity to risk taking. Social Cognitive and Affective Neuroscience, 10, 389-398. doi:10.1093/scan/nsu064

Terry-McElrath, Y. M., O’Malley, P. M., \& Johnston, L. D. (2009). Reasons for drug use among American youth by consumption level, gender, and race/ethnicity: 1976-2005. Journal of Drug Issues, 39, $677-714$.

Troje, N. F., \& Bülthoff, H. H. (1996). Face recognition under varying poses: The role of texture and shape. Vision Research, 36, 1761-1771. doi:10.1016/0042-6989(95)00230-8

van der Kouwe, A. J., Benner, T., Fischl, B., Schmitt, F., Salat, D. H., Harder, M., ... Dale, A. M. (2005). On-line automatic slice positioning for brain MR imaging. NeuroImage, 27, 222-230. doi:10.1016/j. neuroimage.2005.03.035

van der Kouwe, A. J., Benner, T., Salat, D. H., \& Fischl, B. (2008). Brain morphometry with multiecho MPRAGE. NeuroImage, 40, 559-569. doi:10.1016/j.neuroimage.2007.12.025

Weissman, D. G., Schriber, R. A., Fassbender, C., Atherton, O., Krafft, C., Robins, R. W., ... Guyer, A. E. (2015). Earlier adolescent substance use onset predicts stronger connectivity between reward and cognitive control brain networks. Developmental Cognitive Neuroscience, 16, 121-129. doi:10. 1016/j.den.2015.07.002

Welborn, B. L., Lieberman, M. D., Goldenberg, D., Fuligni, A. J., Galvan, A., \& Telzer, E. H. (2016). Neural mechanisms of social influence in adolescence. Social Cognitive and Affective Neuroscience, 11, 100-109. doi:10.1093/scan/nsv095

Whitney, P., Rinehart, C. A., \& Hinson, J. M. (2008). Framing effects under cognitive load: The role of working memory in risky decisions. Psychonomic Bulletin \& Review, 15, 1179-1184. doi:10. 3758/PBR.15.6.1179

Wilkinson, S. T., Stefanovics, E., \& Rosenheck, R. A. (2015). Marijuana use is associated with worse outcomes in symptom severity and violent behavior in patients with posttraumatic stress disorder. Journal of Clinical Psychiatry, 76, 1174-1180. doi:10.4088/JCP. $14 \mathrm{~m} 09475$

Wise, R. A. (1996). Neurobiology of addiction. Current Opinion in Neurobiology, 6, 243-251.

Woolrich, M. W., Jbabdi, S., Patenaude, B., Chappell, M., Makni, S., Behrens, T., ... Smith, S. M. (2009). Bayesian analysis of neuroimaging data in FSL. NeuroImage, 45(Suppl. 1), S173-S186. doi:10.1016/j.neuroimage.2008.10.055

Worsley, K. J. (2001). Statistical analysis of activation images. Oxford: Oxford University Press.

Zaki, J., Schirmer, J., \& Mitchell, J. P. (2011). Social influence modulates the neural computation of value. Psychological Science, 22, 894-900. doi:10.1177/0956797611411057 